\title{
AVALIAÇÃO DE GOMA XANTANA E CARBOXIMETILCELULOS EM PÃES PARA CELÍACOS
}

Krischina Singer APLEVICZ ${ }^{1}$

Julia Prudêncio MOREIRA ${ }^{2}$

\begin{abstract}
${ }^{1}$ Doutora em Ciências dos Alimentos, Professora do Instituto Federal de Santa Catarina, aplevicz@gmail.com ${ }^{2}$ Bolsista do curso Técnico em Panificação e Confeitaria do Instituto Federal de Santa Catarina, julinhah_pm@hotmail.com
\end{abstract}

\section{Recebido em: 19/02/2015 - Aprovado em: 13/06/2015 - Disponibilizado em: 15/07/2015}

RESUMO: A doença celíaca é caracterizada por lesão permanente da mucosa intestinal provocada pela ingestão de glúten. O objetivo desta pesquisa foi verificar a influência da aplicação da goma xantana e carboximetilcelulose em pães sem glúten. As análises microbiológicas de coliformes e salmonella $s p$ foram realizadas. A análise sensorial foi aplicada em 30 julgadores não-treinados aplicando o teste de preferência utilizando o teste estatístico não-paramétrico de Friedman. O pão com maior preferência foi submetido às análises físico-químicas de umidade, cinzas, lipídios e proteínas. As análises microbiológicas de coliformes e salmonella $s p$ dos pães apresentaram resultados dentro dos padrões da legislação. O pão com maior preferência foi a amostra controle e o menos preferido foi o com carboximetilcelulose. $\mathrm{Na}$ análise físico-química foi observado um alto teor de umidade e de proteínas nos pães.

Palavras-chave: doença celíaca, goma xantana, carboximetilcelulose.

\section{EVALUATION OF XANTHAN GUM AND CARBOXIMETILCELULOS IN GLUTEN-FREE BREAD}

\begin{abstract}
Celiac disease is characterized by permanent damage of the intestinal mucosa caused by the ingestion of gluten. The objective of this research was to investigate the influence of the application of xanthan gum and carboxymethylcellulose in gluten-free breads. Microbiological analyzes of coliforms and salmonella sp were performed. Sensory analysis was applied to 30 non-trained judges using preference test using the nonparametric statistical test of Friedman. The bread was more preferably subjected to physicochemical analysis of moisture, ash, fat and protein. Microbiological analyzes of coliforms and salmonella sp showed results within the standards. The bread was more preferably control and the least preferred was with carboxymethylcellulose. In physico-chemical analysis showed a high content of moisture and protein breads.

Keywords: celiac disease, xanthan gum, carboxymethylcellulose.
\end{abstract}

\section{INTRODUÇÃO}

A doença celíaca consiste em uma enteropatia por sensibilidade ao glúten em indivíduos predispostos geneticamente. A doença é caracterizada por lesão permanente da mucosa intestinal provocada pela ingestão de glúten, podendo haver a recuperação completa da mucosa em decorrência da remoção do glúten da dieta (MELO et al., 2006). Segundo a Organização Mundial de Saúde (WHO, 2001), cerca de 1 entre cada 300 a 3000 indivíduos são afetados pela doença celíaca mundialmente, dependendo da região geográfica específica. Para o celíaco, o consumo de alimentos contaminados com glúten, mesmo que em 
pequenas quantidades, agrava a sua condição patológica e deteriora seu estado nutricional (MARCILIO et al., 2005). Além da dieta sem glúten, o celíaco pode apresentar intolerância à lactose tendo a redução da quantidade de enzima lactase devido ao atrofiamento da vilosidade de seu intestino (RIO SEM GLÚTEN, 2010).

O glúten é uma proteína insolúvel presente no trigo, aveia, cevada e centeio (AUGUSTO et al., 2002). Apenas algumas partes do glúten são prejudiciais e tóxicas ao intestino do indivíduo intolerante ao glúten, que recebem nomes diferentes para cada cereal: no trigo é a gliadina; na cevada é a hordeína; na aveia é a avenina e no centeio é a secalina (ACELBRA, 2004). O glúten poderá ser substituído pelo milho (farinha de milho, amido de milho, fubá), arroz (farinha de arroz), batata (fécula de batata) e mandioca (farinha de mandioca e polvilho) (AUGUSTO et al., 2002). Por faltarem produtos industrializados sem glúten no mercado brasileiro, a maior parte das preparações do cardápio do paciente celíaco é caseira, demandando tempo e dedicação para o preparo (CÉSAR et al., 2006).

A substituição do glúten da farinha de trigo por outro ingrediente é desafiante, pois este representa a rede protéica que retém o gás carbônico, produzido no processo de fermentação e ocasionando expansão da massa (CÉSAR et al., 2006). A matriz do glúten é um dos principais determinantes das características reológicas das massas, tais como elasticidade, extensibilidade, resistência ao estiramento e habilidade de retenção de gás (LAZARIDOU et al., 2007).

Goma xantana, locusta, guar e carboximetilcelulose são utilizadas para melhoria de textura e aumento de vida de prateleira dos produtos de panificação. Estes hidrocolóides também podem reter a umidade ou diminuir a taxa de desidratação, proporcionando aumento de vida de prateleira e melhoria das características sensoriais (MUNHOZ, 2003). O objetivo deste estudo foi verificar a influência da adição de goma xantana e carboximetilcelulose (CMC) em pães para celíacos.

\section{MATERIAIS E MÉTODOS}

\section{Formulação do pão}

Foram desenvolvidas três formulações de pães: A - controle; B goma xantana; C - com carboximetilcelulose; conforme Tabela 1. Os pães foram preparados pelo método direto. Primeiramente foram misturados os ingredientes secos como: farinha de arroz, farinha de soja, fécula de batata, sal, açúcar, goma xantana ou carboximetilcelulose. Em seguida, foi 
adicionado água, ovos e óleo de milho. Após a mistura dos ingredientes, o pão foi fermentado por $30 \mathrm{~min} / 38^{\circ} \mathrm{C}$. A massa foi acondicionada em forma de bolo inglês untada com óleo de milho e polvilhada com farinha de arroz. Os pães foram assados em forno a vapor por $20 \mathrm{~min} / 165$ ${ }^{\circ} \mathrm{C}$.

Tabela 1 - Formulação do pão para celíaco

\begin{tabular}{lccc}
\hline \multicolumn{1}{c}{ Ingredientes (\%) } & A & B & C \\
\hline água & 60 & 60 & 60 \\
farinha de arroz & 50 & 50 & 50 \\
farinha de soja & 50 & 50 & 50 \\
ovos & 50 & 50 & 50 \\
óleo de milho & 10 & 10 & 10 \\
fécula de batata & 5 & 5 & 5 \\
açúcar refinado & 2 & 2 & 2 \\
fermento biológico seco & 3 & 3 & 3 \\
sal & 3 & 3 & 3 \\
goma xantana & - & - & 1 \\
carboximetilcelulose & - & 1 & - \\
\hline
\end{tabular}

Legenda: A - controle; B - goma xantana; C - carboximetilcelulose.

\section{Análise microbiológica}

As análises de coliformes e Salmonella sp (APHA, 2001) foram realizadas pelo Laboratório de Microbiologia do Departamento de Ciência e Tecnologia dos Alimentos da Universidade Federal de Santa Catarina.

\section{Análise sensorial dos pães}

As amostras dos pães foram analisadas por 30 julgadores não treinados $(n=30)$, cada um avaliando 3 amostras e baseando a avaliação na impressão global dos produtos. Os julgadores foram convidados a classificar as amostras em ordem de preferência. As amostras mais preferidas tiveram nota de ordenação 3 e as menos preferidas nota de ordenação 1 . As amostras foram servidas em pratos plásticos brancos e codificadas com números de três dígitos aleatórios. Água mineral foi fornecida para enxaguar a boca entre as avaliações (MEILGAARD et al., 2007). Foi aplicado um questionário para se obter informações sobre os julgadores.

\section{Análises físico-químicas}

O pão mais preferido na análise sensorial foi submetido as análises de umidade, cinzas e lipídios de acordo com a metodologia do Instituto Adolfo Lutz (2005) e de proteínas de acordo com AOAC (2005). 


\section{Análise estatística}

Os resultados das análises foram analisados utilizando o programa Statistica ${ }^{\circledR}$ versão 8.0 (Statsoft Inc., Tulsa, OK, USA). Os valores obtidos nas análises sensoriais foram avaliados estatisticamente pelo teste não-paramétrico de Friedman (MEILGAARD et al., 2007) utilizando o programa Bioestatisc 5.0.

\section{RESULTADOS E DISCUSSÃO}

As análises microbiológicas de coliformes e salmonella $s p$ dos pães apresentaram resultados satisfatórios, dentro dos padrões exigidos pela Agência Nacional de Vigilância Sanitária.

A análise sensorial dos produtos foi realizada aplicando o teste de ordenação-preferência. Não foi encontrada diferença significativa entre os tratamentos A e B, porém a maior preferência foi dada ao pão controle. A amostra com menor preferência foi a com carboximetilcelulose ( $\mathrm{P}<0.05)$. Os valores médios da análise sensorial estão ilustrados na Tabela 2. Com relação a participação no teste, foi observado que $73 \%$ foram mulheres. Do total de julgadores, $43 \%$ relataram que consomem pão uma vez ao dia e $37 \%$ duas vezes ao dia.
Tabela 2 - Resultados do teste de ordenaçãopreferência

\begin{tabular}{cc}
\hline Amostras & Médias \\
\hline A & $70^{\mathrm{a}}$ \\
B & $63^{\mathrm{a}}$ \\
C & $48^{\mathrm{b}}$ \\
\hline
\end{tabular}

Valores médios na mesma coluna seguidos por letras diferentes estatisticamente diferentes $(\mathrm{P}<0.05)$.

O resultado da remoção do glúten da formulação de produtos de panificação corresponde na maioria dos problemas evidenciados com esse tipo de produto. Muitos dos produtos sem glúten disponíveis no mercado apresentam baixa aceitabilidade pelos consumidores quanto ao sabor (GALLAGHER et al., 2004).

Segundo comentários dos participantes, a amostra $\mathrm{A}$ foi a mais preferida devido a sua maciez, maior volume, possuir alvéolos mais definidos, casca com boa textura e sabor mais acentuado de gordura. Alguns julgadores relataram que não apreciaram o sabor das amostras em geral, fato esse que deve estar relacionado ao não consumo de produtos sem glúten. Na Figura 1 está ilustrado os pães sem glúten.

Lopez et al. (2004) testaram formulações de pães com misturas de farinhas de milho e arroz e fécula de mandioca juntamente com os demais ingredientes, incluindo margarina e goma 
xantana. A mistura composta por $45 \%$ de farinha de arroz, $35 \%$ de amido de milho e $20 \%$ de amido de mandioca apresentou um bom resultado, originando pães com miolo composto por células de tamanhos uniformes, bem distribuídas, sabor e aparência agradável.

Figura 1 - Pães para celíacos: controle (A), goma xantana (B) e carboximetilcelulose (C)

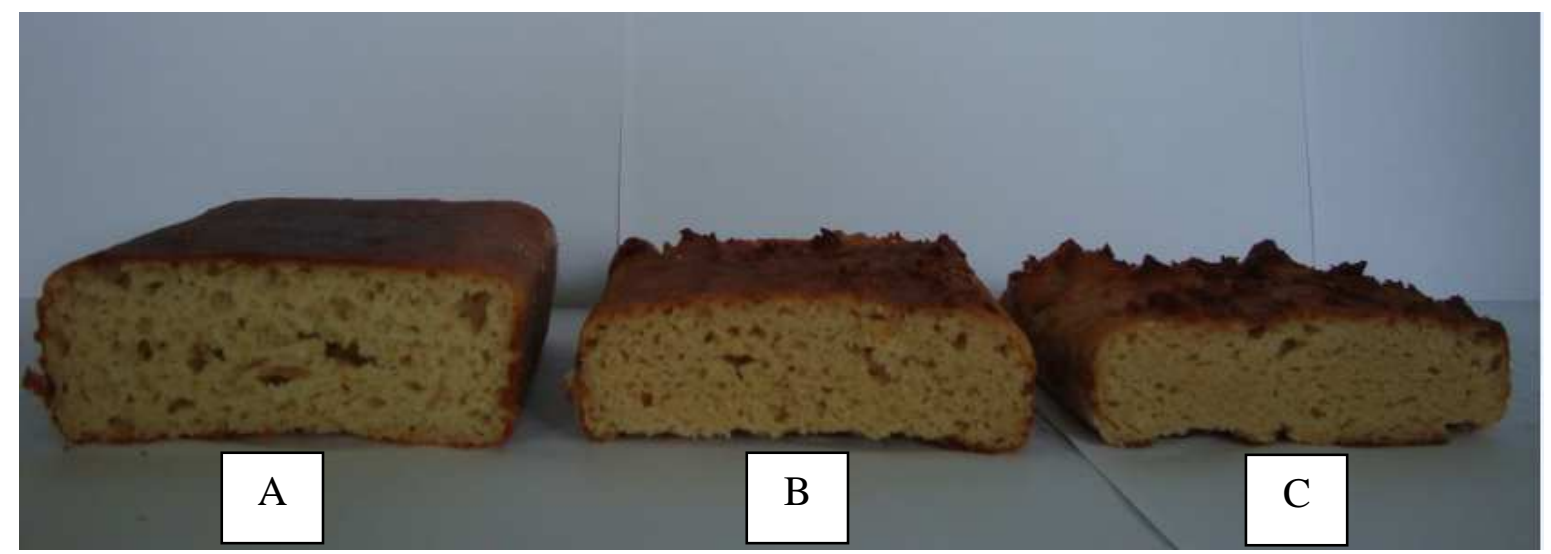

Pequena quantidade de estão na Tabela 3. Observa-se um teor alto hidrocolóides, menor que $1 \%$ sobre o peso de umidade de 43,04\%. Freire (2011) da farinha, aumentam a absorção de água, relatou que os produtos de panificação com o volume específico do pão, reduzem a firmeza do pão e a retrogradação do amido elevada atividade de água podem ser colonizados por fungos.

(COLLAR et al., 1999).

Preichardt et al. (2009) afirmaram em sua pesquisa que a adição de goma amostra controle xantana melhorou as características sensoriais dos bolos, retardando 0 envelhecimento, reduzindo a formação de migalhas e aumentando a sensação de umidade na boca.

\begin{tabular}{cc}
\hline Análises & $(\boldsymbol{\%} \mathbf{p} / \mathbf{p})$ \\
\hline umidade & $43,04 \pm 0,08$ \\
cinzas & $2,83 \pm 0,01$ \\
gordura & $12,34 \pm 0,04$ \\
proteína & $14,24 \pm 0,12$ \\
\hline
\end{tabular}

O pão controle foi submetido a análise de composição físico-química, por ter sido o mais preferido entre os julgadores. Os resultados dessas análises 
presente na formulação. Como ressalta Ribeiro (2006), a soja é frequentemente adicionada a outros alimentos para aumentar o valor nutricional de farinhas, como: a de trigo, a de milho e a de mandioca; e substituir fontes protéicas mais caras, por exemplo, as carnes, constituindo uma fonte protéica de qualidade e, ao mesmo tempo, de baixo custo. Pereira et al. (2013) elaboraram pão de batata substituindo creme de arroz por chia e obteve valores médios maiores umidade e menores para lipídios, proteínas e cinzas.

\section{CONCLUSÃO}

As análises microbiológicas de coliformes e salmonella sp dos pães apresentaram resultados satisfatórios, dentro dos padrões exigidos pela Agência Nacional de Vigilância Sanitária. O pão mais preferido na análise sensorial foi o pão controle e o menos preferido foi o com carboximetilcelulose. $\mathrm{Na}$ análise físicoquímica foi observado um alto teor de umidade e de proteínas nos pães.

\section{REFERÊNCIAS}

ACELBRA. Associação dos celíacos do http://www.acelbra.org.br/2004/doencaceli aca.php. Acesso em 18 de abril de 2011.

APHA. American Public Health Association. Compendium of Methods of the Microbiological Examination of Foods. 4th. Edition. Washington D.C., 2001.

AOAC. Association of Official Analytical Chemists. Official methods of the AOAC International, 18 th ed. Maryland/ USA: AOAC, 2005.

AUGUSTO, A.P.; ALVES, D.C.; MANNARINO, I.C. Terapia Nutricional. São Paulo: Atheneu, 2002.

CÉSAR, A. S.; GOMES, J.C.; STALIANO, C.D.; FANNI, M.L.; BORGES, M.C. Elaboração de Pão sem Glúten, Revista Ceres, v. 53, n. 306, p. 150-155, 2006.

COLLAR, C.; ANDREU, P.; MARTNEZ, J.C.; ARMERO, E. Optimization of hydrocolloid addition to improve wheat bread dough functionality: a response surface methodology study. Food hydrocolloids, v.13, p. 467-475, 1999.
Brasil.
Disponível
em 
FREIRE, F. das C.O. A deterioração fúngica de produtos de panificação no Brasil. Comunicado técnico Embrapa. 2011. Disponivel em < www.cnpat.embrapa.br/download_publica cao.php?id=319>. Acesso em 05 de março de 2014.

GALLAGHER， E.; GORMLEY， T.R.; ARENDT, E.K. Recent advances in the formulation of gluten-free cereal-based products. Trends in Food Science and Technology, v.15, p. 143-152, 2004.

IAL. Instituto Adolfo Lutz. Normas Analíticas do Instituto Adolfo Lutz, v.1: Métodos químicos e físicos para análise de alimentos, 4 ed. Brasília: Editora MS, 2005.1018p.

LAZARIDOU, A.; DUTA, D.; PAPAGEORGIOU, M.; BELC, N.; BILIADERIA, C.G. Effects of hydrocolloids on dough rheology and bread quality parameters in gluten-free formulations. Journal of Food Engineering, v. 79, n.3, p. 1033-1047, 2007.

LÓPEZ, A. C. B.; PEREIRA, A.J.G.; JUNQUEIRA, R.G. Flour mixture of rice flour, corn and cassava starch in the production of gluten-free white bread.
Brazilian Archives Biology Technology, v. 47, n. 1, p. 63- 70, 2004.

MARCILIO, R.; AMAYA-FARFAN, J.; SILVA. M.A.A.P. da. Avaliação da farinha de amaranto na elaboração de biscoito sem glúten do tipo cookie. Brazilian Journal of Food Technology, v. 8, n. 2, p.175-181, 2005.

MEILGAARD， M.; CIVILLE， G. V.; CARR, B. T. Sensory Evaluation Techniques. 4th ed. FL: CRC Press, 2007.

MELO, S.B.C.; FERNANDES, M.I.; PERES, L.C.; TRONCON, L.E.; GALVÃO, L.C. Prevalence and demographic characteristics of celiac disease among blood donors in Ribeirao Preto, State of Sao Paulo, Brazil. Digestive Diseases and Sciences, v. 51, n. 5, p.10201025, 2006.

MUNHOZ, M.P. Influência dos hidrocolóides na qualidade tecnológica de pães. São Paulo, 2003. Dissertação (Mestrado em Tecnologia de Alimentos) Universidade Estadual de Campinas. 2003.

PEREIRA, B. da S.; PEREIRA, B. da S.;CARDOSO, E. dos S.; MENDONÇA, J.O.B.; SOUZA, L.B.de SANTOS,M.P. do; ZAGO, L.; FREITA, S.M. de L. Análise físico-química e sensorial do pão de batata isento de glúten enriquecido com 
farinha de chia. Demetra, v. 8, n. 2, p. 125-136, 2013.

PREICHARDT, L. D.; VENDRUSCOLO, C.T.; GULARTE, M.A.; MOREIRA, A.DA S. Efeito da goma xantana nas características sensoriais de bolos sem glúten. Revista Brasileira de Tecnologia Agroindustrial, v. 3, n. 1, p.70-76, 2009.

RIBEIRO, V. A. Aproveitamento do resíduo do extrato de soja na elaboração de um produto tipo paçoca. Lavras, 2006. 75p. Dissertação (Mestrado em Ciência dos Alimentos) - Universidade Federal de Lavras, 2006.

RIO SEM GLÚTEN. Disponível em $<$ http://www.riosemgluten.com/Guia_Orie ntador_para_Celiacos_2010.pdf>. Acesso em 18 de abril de 2011.

\section{WORLD HEALTH ORGANIZATION}

(WHO). Evaluation of allergenicity of genetically modified foods. Report of a joint $\mathrm{FAO} / \mathrm{WHO}$ expert consultation on allergenicity of foods derived from biotechnology, 22-25 January - Food and Agriculture Organization of the United Nations (FAO), Rome, Italy, 2001. 